\title{
PERANCANGAN INTERIOR PET MEDICARE DI KOTA BLITAR
}

\author{
Irfa Kurnia', Ahmad Fajar Ariyanto \\ ${ }^{1}$ Program Studi S-1 Desain Interior \\ Fakultas Seni Rupa dan Desain Institut Seni Indonesia (ISI) Surakarta \\ E-mail: iphapa@gmail.com \\ ${ }^{2}$ Program Studi S-1 Desain Interior \\ Fakultas Seni Rupa dan Desain Institut Seni Indonesia (ISI) Surakarta \\ E-mail: leahfajar@yahoo.cm
}

\begin{abstract}
Every person has a tendency to love something and do a deep research into that activity. Daily routine drains energy of the people. That is why, hobby, such as taking care of pets become a refreshing activity that 'recharge' the energy that has been depleted. Pet hobby has become a trend and spreads to even remote areas, especially Blitar City. Communities such as Munchkin Minuet Cats, Brotherhood Gamedog (BROGAD), Kucing Addict, KDC and Canine were born in Blitar, but the facilities for fulfilling the needs of both pet dogs and cats are extremelyy limited. Only some pet food outlets and animal clinics which were not enough to complete the needs in one place (one stop service). That is why The Interior Design of Pet Medicare in Blitar City is going to answer that problem. Pet Medicare is there with many facilities that includes Medic, Care, Playspace, Meeting and Store that combine origami design theme with contemporary style. Origami that famous for its animal forms is packed with contemporary style which is so up-to-date and make it an interesting place for pet-lovers, veterinarians, and also animal owners.
\end{abstract}

Keywords: Pet, Medicare, Blitar, Animal, Pets.

\section{PENDAHULUAN}

Modernisasi pada akhirnya memberikan dampak pada berbagai aspek. Dari sisi ekonomi tentunya modernisasi memberikan dampak pada kemajuan system ekonomi masyarakat Indonesia saat ini. Selain sektor ekonomi, dampak modernisasi juga dirasakan pada bidang sosial. Setiap orang memiliki kecenderungan untuk menyukai suatu hal dan mendalaminya dengan bentuk berkegiatan. Salah satu dari sekian banyak hobi yang ada di masyarakat saat ini yang cukup menyita perhatian adalah kegemaran terhadap hewan peliharaan. Kegiatan masyarakat yang padat menimbulkan rasa jenuh sehingga kegiatan hobi tersebut dapat menjadi penghilang rasa penat setelah beraktivitas pekerjaan.

Umumnya hewan peliharaan yang diminati adalah anjing dan kucing, meskipun pada perkembangannya mulai muncul minat pada hewan lain seperti reptil, dan beberapa jenis unggas. Saat ini memiliki hewan peliharaan tidak hanya sebagai penyalur hobi maupun sebagai teman, namun membawa keuntungan karena hewan yang dipelihara tak jarang memiliki nilai ekonomi yang tinggi jika diperjualbelikan. Kegiatan hobi memelihara hewan peliharaan terjadi di berbagai tempat. Jika mulanya kegiatan semacam ini diikuti oleh kalangan warga perkotaan besar dan berkesan elit, namun saat ini kegiatan tersebut telah menyebar bahkan di daerah-daerah kecil 
di Indonesia, dengan peminat yang semakin beragam tentunya.

Kegiatan semacam ini di Blitar ini mulai terlihat dan telah berdiri beberapa komunitas yang menjadi wadah kegiatan hobbies, mereka Munchkin Minuet Cats, Brotherhood Gamedog (BROGAD), Kucing Addict, KDC, Canine, yang berada di Blitar dan sekitarnya. Akan tetapi hanya terdapat beberapa outlet penjual makanan hewan, dan beberapa klinik dokter hewan dengan tempat yang terpisah. Seiring dengan munculnya minat masyarakat terhadap hobi tersebut, maka dipandang perlu adanya fasilitas yang mampu mencangkup segala kebutuhan terkait hewan peliharaan dalam satu tempat (one stop service). Melihat potensi pasar di Blitar yang mayoritas adalah peminat hobi pemelihara kucing dan anjing, maka Pet Medicare ini terfokus pada pelayanan kebutuhan hewan peliharaan anjing dan kucing. Mengutip sebuah pernyataan mengenai pentingnya pelayanan kesehatan pada hewan berikut,

"Dewasa ini masalah kesehatan hewan harus dipandang sebagai masalah kesehatan semesta, yang memerlukan pendekatan paradigma "one world, one health, one medicine". Hal ini mengandung implikasi pentingnya penyelesaian masalah kesehatan hewan secara tuntas dan berkesinambungan dalam suatu sistem kesehatan hewan nasional" 1

maka perancangan Pet Medicare adalah sebuah solusi bagi para hobbies di Blitar, khususnya pemelihara anjing dan kucing dalam memenuhi kebutuhan peliharaannya. Maka perancangan Pet Medicare adalah sebuah solusi bagi para hobbies di Blitar, khususnya pemelihara anjing dan kucing dalam memenuhi kebutuhan peliharaannya.

1 Peraturan Menteri Pertanian Nomor: 02/Permentan/ OT.140/1/2010 tentang Pedoman Pelayanan Jasa Medik Veteriner
Persyaratan Minimal untuk Fasilitas Kategori Klinik Hewan adalah Ruang Pelayanan yang terdiri atas Ruang Tunggu, Ruang Periksa, Ruang Tindakan, Ruang Preparasi, Ruang Operasi, dan Ruang Rawat Inap. Ruang penunjang terdiri dari Ruang Cuci Alat dan Kain Operasi, Ruang Rapat, Ruang Perpustakaan, dan Ruang Obat. Jasa pelayanan meliputi konsultasi dan terapi, vaksinasi, operasi (minor, mayor), rawat inap dan isolasi, pemeriksaan labratorium, UGS, Xray, UGD. ${ }^{2}$

Dari kutipan di atas, maka perlu adanya fasilitas yang mampu mengakomodir segala kebutuhan hewan peliharaan dalam satu tempat. Oleh karena itu pada Pet Medicare disediakan beberapa fasilitas seperti grooming untuk memenuhi fasilitas kecantikan dan kebersihan tubuh hewan peliharaan, Medic Area untuk memenuhi fasilitas pelayanan medis yang terdiri dari ruang konsultasi, ruang operasi, X-Ray, Laboratorium. Store Area sebagai area untuk transaksi penjualan yang menyediakan berbagai keperluan hewan peliharaan dari makanan, obat-obatan, hingga kebutuhan lain seperti kandang, pakaian dan aksesoris.

Site plan Pet Medicare adalah di Jalan Batanghari, Kota Blitar. Daerah ini terletak di pinggiran kota, sehingga udara di daerah ini jauh dari pengaruh polusi. Selain itu letaknya yang tidak berjauhan dengan Pasar Hewan Blitar, menjadi nilai tersendiri bagi para hobbies untuk memenuhi fasilitas yang dibutuhkannya.

Fasilitas pelayanan kesehatan tentu harus mengutamakan faktor higenis namun tetap nyaman baik bagi pengunjung (pemilik hewan), pengelola, maupun pasien (hewan). Selain itu, suasana yang bersih dan nyaman juga mampu menstimulasi kesembuhan bagi hewan yang sakit. Guna mendukung hal tersebut, perlu

2 Peraturan Menteri Pertanian No.2. (2009). Pedoman Pelayanan Jasa Medik Veteriner 
adanya sebuah konsep desain yang menarik sehingga mendukung aktivitas dan citra Pet Medicare dengan tema origami. Origami pada saat ini dikenal memiliki beragam bentuk dengan skema warna yang beragam, sehingga sangat cocok membawakan suasana ceria pada Pet Medicare. Suasana ceria akan memberikan kenyamanan bagi hewan peliharaan dan memicu kesembuhan bagi pasien (hewan peliharaan).

Perancangan Pet Medicare di Kota Blitar merupakan wujud dari kepedulian terhadap kebutuhan akan fasilitas kesehatan khusus untuk hewan peliharaan yang sampai saat ini belum terpenuhi secara maksimal. Maraknya masyarakat Blitar saat ini yang mulai berbondong-bondong mengikuti trend ${ }^{3}$. Untuk mewujudkan hal tersebut diperlukan beberapa pendekatan untuk menemukan pemecahan masalah desain. Pendekatan yang dipilih meliputi

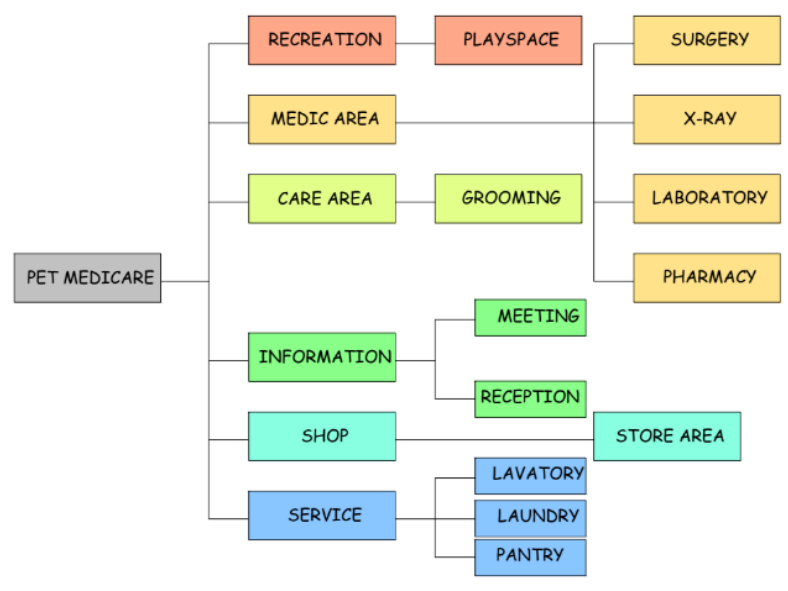

Skema 01. Skema Pembagian area berdasarkan pendekatan fungsi

3 tren /trén/ $n$ gaya mutakhir; mengetren/ me $\cdot$ nge $\cdot$ tren/ a bergaya mutakhir; bergaya modern: (Kamus Besar Bahasa Indonesia Edisi ke III, (Jakarta, Balai Pustaka). Hal 1210 ) a. Rekreasi

Berupa Playspace untuk mengantrikan hewan peliharaan sebelum menerima layanan perawatan. Area ini berupa Dog Room atau Cat Room yang didesain khusus agar hewan yang berada di dalamnya dapat leluasa bermain seperti tingga di rumahnya sendiri.

b. Medis

\section{Surgery}

Surgery atau bedah adalah area untuk memberikan tindakan medis berupa bedah, terdiri dari ruang bedah, ruang intensif (untuk perawatan pasca operasi), ruang isolasi, dan ruang dokter untuk keperluan konsultasi dan pemeriksaan. Area ini tentu saja akan dipisah dan dikelompokkan berdasarkan jenis hewan yang akan memperoleh perawatan.

\section{Radiology}

Radiology adalah area khusus yang diperuntukkan untuk keperluan pengambilan foto rontgen menggunakan radiasi sinar $\mathrm{X}$. Persyaratan ruang untuk Rekam X-Ray diatur secara resmi dalam Perka BAPETEN No. 08 Tahun 2011. ${ }^{4}$

\section{Laboratory}

Area khusus untuk uji laborat guna menentukan diagnosa terhadap suatau kasus secara valid. Area ini memerlukan privasi sehingga bersifat tertutup dan harus terjaga kesterilannya.

\section{Pharmacy}

Area ini merupakan tempat staf

$4 \quad$ BAPETEN (Badan Pengawas Tenaga Nukir) Pedoman layanan perizinan Radiodiagnostik dan Intervensional. Direktorat Perizinan Fasilitas Kesehatan dan zat Radioaktif.2014. Hal : 16 
farmasi meracik obat sesuai resep yang dituliskan dokter. Bagian ruang ini termasuk area privat yang tidak dapat diakses oleh sembarang pengunjung.

\section{c. Care Area}

Terdiri dari ruang untuk memberikan pelayanan Grooming basah dan kering, dimana Grooming basah pelayanannya berupa pembersihan dengan air (mandi), sedangkan Grooming kering kegiatannya berupa kegiatan kering seperti cukur, potong, dan styling.

\section{d. Information}

\section{Meeting Hall}

Ruang yang digunakan untuk mengadakan pertemuan, melakukan Workshop dan seminar.

\section{Reception Area}

Area penerimaan atau resepsionis, sebagai pusat informasi dan administrasi.

\section{Meeting Room}

Ruang ini digunakan untuk mengadakan pertemuan berupa rapat yang bersifat internal.

\section{e. Service}

Terdiri dari ruangan Pantry, Laundry, dan Lavatory

\section{Pendekatan Ergonomi}

Ergonomi adalah ilmu yang mempelajari ilmu terapan yang berusaha untuk menyerasikan pekerja dengan lingkungan kerjanya atau sebaliknya, dengan tercapainya produktifitas dan efisiensi yang setinggi-tingginya melalui pemanfaatan manusia seoptimalnya. Sasaran ergonomi adalah agar tenaga kerja dapat mencapai prestasi kerja yang tinggi (produktif) tetapi dalam suasana yang aman dan nyaman. ${ }^{5}$

Adapun fasilitas ruang dan pendukung ruang yang dibutuhkan perancangan Interior Pet Medicare di Blitar adalah Reception Area, Office, Medic Area, Locker, Care Area, Pantry, Store, Lavatory, Meeting hall, Meeting Room

\section{Pendekatan Tema/Gaya}

Tema Perancangan Desain Interior Pet Medicare di Blitaradalah Origami menggunakan gaya kontemporer yang menonjolkan bentuk unik, diluar kebiasaan, atraktif dengan permainan warna yang menjadi modal utama dalam menciptakan daya tarik bangunan. Kontemporer berasal dari kata "co" (bersama) dan "tempo" (waktu) sehingga kontemporer secara tematik merefleksikan waktu yang telah dilalui, begitu pula dengan desain sehingga berkesan kreatif dan modern. Kata kontemporer sendiri bisa diartikan sebagai sesuatu yang serba uptodate, ditandai dengan perubahan desain yang selalu berusaha menyesuaikan dengan waktu dan eranya. Perubahan desain itu diringi oleh perubahan bentuk, tampilan, jenis material, proses pengolahan, dan teknologi yang dipakai. ${ }^{6}$

\section{Pendekatan Warna}

Berikut beberapa pemilihan warna cerah yang disimpulkan berdasarkan analisa tema dan gaya yang nantinya akan menjadi colour scheme dalam perancangan Pet Medicare di Blitar:

$5 \quad$ Sunarmi, Ergonomi dan Aplikasinya pada Kriya (Surakarta: STSI Surakarta,2001), hal 4.

6 D Susanti. Pusat Fashion Kontemporer Yogyakarta. (Yogyakarta: Universitas Atma Jaya Yogyakarta, 2011) Hal: 21 
Tabel 01. Efek Psikologis Warna Menurut Faber Barren dan John F. Pile (Sumber: Darmaprawira 2002)

\begin{tabular}{|c|l|}
\hline Warna & \multicolumn{1}{|c|}{ Effect } \\
\hline Merah & $\begin{array}{l}\text { Panas, menggairahkan dan mer- } \\
\text { angsang, menarik perhatian }\end{array}$ \\
\hline Jingga & $\begin{array}{l}\text { Mirip dengan warna merah, } \\
\text { tetapi dalam intensitas yang lebih } \\
\text { rendah }\end{array}$ \\
\hline Kuning & Gembira, humor \\
\hline Hijau & $\begin{array}{l}\text { Ketenangan, menyegarkan, da- } \\
\text { mai, dan membangun }\end{array}$ \\
\hline Biru & $\begin{array}{l}\text { Menentramkan, tenang dana } \\
\text { martabat menyebabkan depresi } \\
\text { dan kemurungan }\end{array}$ \\
\hline Ungu & Artistik, kehalusan dan kesedihan \\
\hline Putih & Bersih, terbuka, dan terang \\
\hline Hitam & Martabat, kesan berat, formal \\
\hline
\end{tabular}

Penglihatan kucing terbatas pada warna biru dan abu-abu, sementara yang lain percaya bahwa penglihatan mata kucing mirip dengan anjing, tetapi dengan corak dan saturasi warna yang kurang kaya. Sedangkan pada anjing Semua benda berwarna kuning, hijau, atau oranye muncul dalam berbagai warna kuning atau kuning-coklat. Ungu, yang terdiri atas merah dan biru, tampak seperti biru murni di mata anjing karena mereka tidak dapat menafsirkan komponen merah. Rona biru-hijau laut dan perairan lainnya akan tampak sebagai abu-abu di mata anjing.

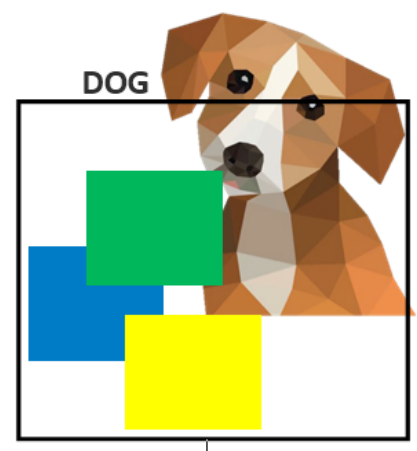

Gambar 01 penglihatan warna pada anjing

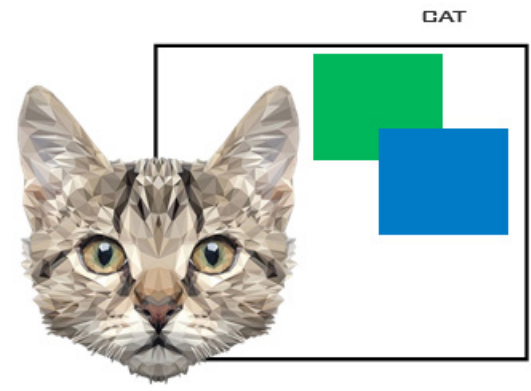

Gambar 02 penglihatan warna pada kucing

\section{PEMBAHASAN}
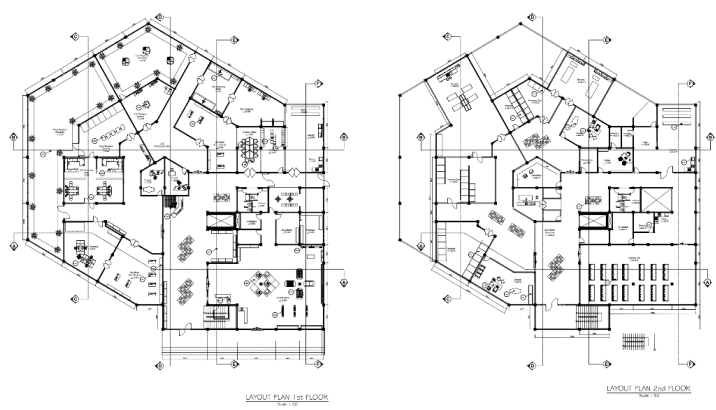

Gambar 03. Rencana Layout Pet Medicare

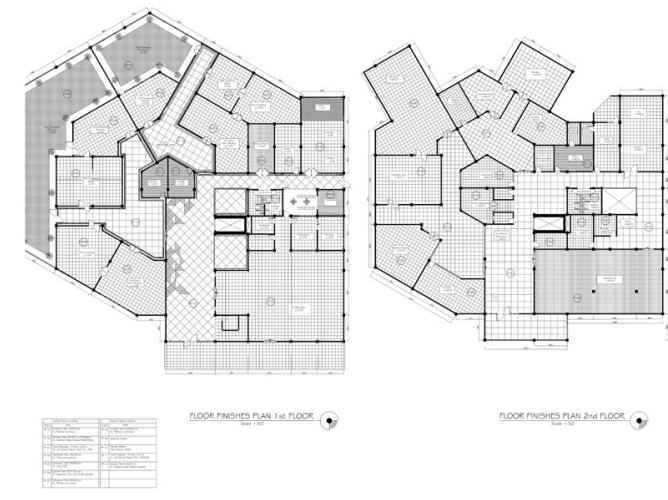

Gambar 04. Rencana Lantai Pet Medicare 

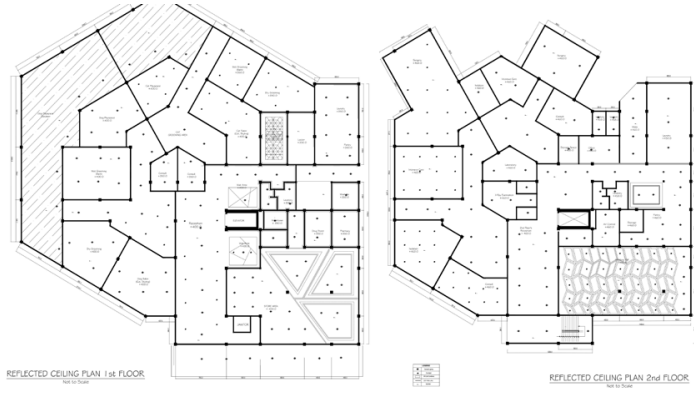

Gambar 05. Rencana Ceiling Pet Medicare

\section{Penerapan Desain}

\section{Reception Area}

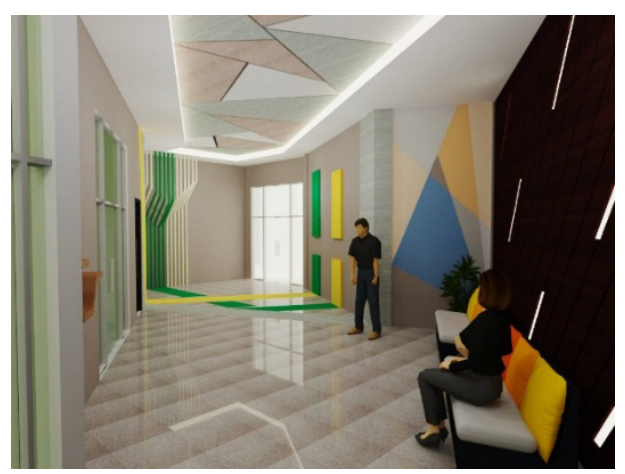

Gambar 06. Reception Area

Dinding ruang menggunakan batu bata plesteran dengan finishing cat dengan warna putih dan abu-abu. Pemilihan warna ini berdasarkan konsep gaya kontemporer yang mengusung warna-warna netral sebagai warna penyeimbang. Beberapa elemen penunjang pada dinding berupa petunjuk arah dipasang pada area menuju grooming anjing dan kucing. List lantai menggunakan material keramik warna netral yaitu hitam.

\section{Store}

Material lantai yang dipilih untuk area ini adalah glossy ceramics tiles dengan skema warna gradasi dari kuning ke jingga. Penataan pola lantai berupa permainan bentuk kotak yang diulang dari rapat ke renggang. Penataan pola lantai yang demikian digunakan untuk memberikan perbedaan yang mencolok pada area display barang. Kombinasi material seperti lantai keramik digunakan sebagai penanda area sirkulasi. Penataan barang diatur terpisah berdasarkan jenisnya, dari peralatan, aksesoris, makanan, produk perawatan, hingga obatobatan.

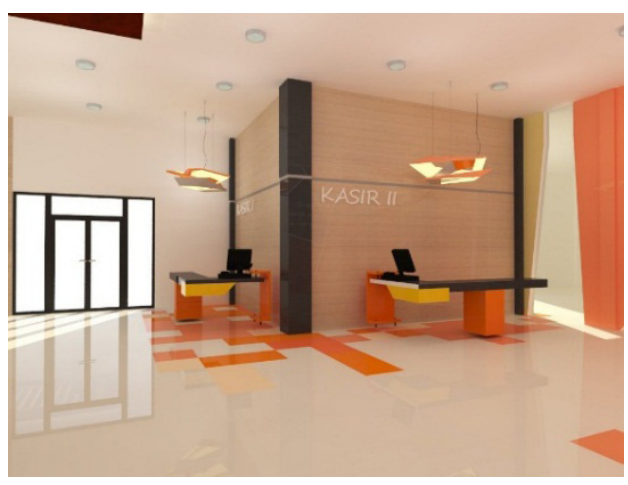

Gambar 07. Store Area

Area Store pada Perancangan Interior Pet Medicare di Kota Blitar ini menggunakan material kaca pada beberapa dinding luar setebal $10 \mathrm{~mm}$. hal ini digunakan untuk memaksimalkan cahaya matahari yang masuk ke dalam ruangan (pencahayaan alami) pada siang hari. Warna dinding yang dipilih adalah gradasi warna kuning ke jingga yang disesuaikan dengan psikologi warna, dimana warna kuning merupakan warna yang menarik perhatian, sehingga pengunjung akan tertarik untuk datang ke tempat ini.
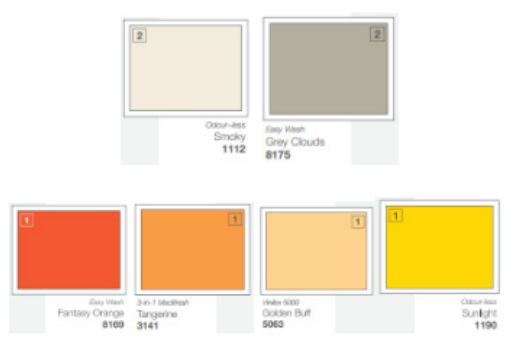

Gambar 08 . Pilihan warna dinding pada Store Area 
Ceiling menggunakan material gypsumboard sebagai material utama, dengan aksen pola menyerupai lipatan kertas origami pada downceiling. Downceiling menggunakan finishing hpl sheet dengan beberapa warna yang berbeda untuk mempertajam bentuk pola.

\section{Area Perawatan}

\section{a. Area Perawatan untuk Kucing}

Area perawatan untuk kucing merupakan area khusus untuk memberikan perawatan grooming pada kucing. Pada area ini terdiri dari beberapa ruang yaitu, salon hewan, ruang memandikan hewan, ruang konsultasi, ruang pengeringan, dan area outdoor untuk bermain hewan peliharaan. Material lantai yang digunakan pada area ini adalah lantai linoleum dengan crak menyerupai kayu parket pada area salon hewan. Pada hall dan area basah menggunakan material granit dengan gloss finishing untuk menunjang kesan bersih. Pada area bermain menggunakan rumput sebagai material penutup yang dikombinasikan dengan area sandbox dibeberapa sisi.

Dinding menggunakan batu bata plesteran dengan finishing cat dinding. Pilihan warna dinding pada area ini menggunakan acuan dari skema warna Nippon Paint Colour Collection cool, clear, and confident. Pilihan warna ini memberikan efek sejuk dan tenang pada ruangan sehingga cocok diaplikasikan pada area ini.

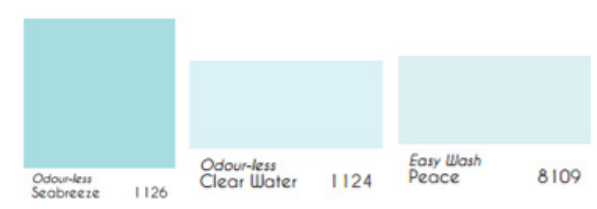

Gambar 09 Pilihan warna dinding pada Care Area

Pada bagian ceiling menggunakan material gypsumboard Ceiling menggunakan material gypsumboard sebagai material utama, dengan aksen berupa softfurnishing berpola perulangan bentuk segitiga dengan permainan warna netra (hitam, putih, abu-abu) memunculkan tema pad area ini.

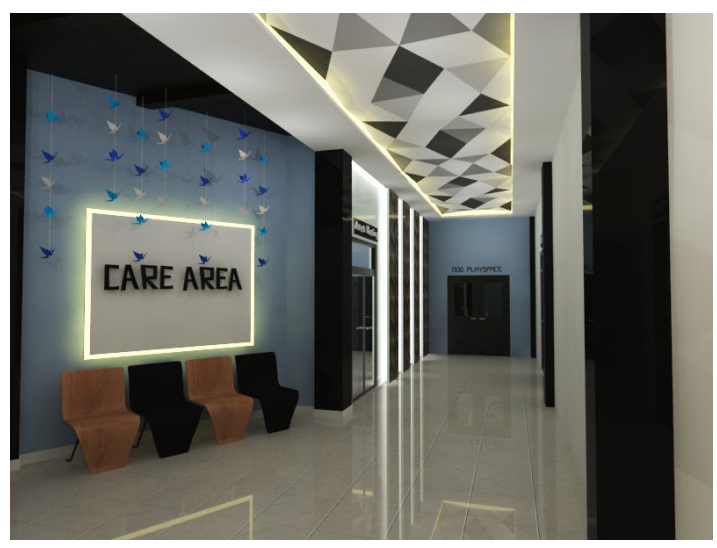

Gambar 10. Care Area

\section{b. Area Perawatan untuk Anjing}

Area perawatan ini merupakan area khusus untuk memberikan perawatan grooming pada anjing. Pada area ini terdiri oleh beberapa ruang yaitu, salon, area basah (memandikan hewan), ruang konsultasi, ruang pengeringan, dan area outdoor untuk bermain hewan peliharaan. Material lantai yang digunakan pada area ini adalah lantai linoleum dengan warna natura seperti beige area salon hewan. Pada hall dan area basah menggunakan material granit dengan gloss finishing untuk menunjang kesan bersih. Pada area bermain kobinasi material rumput, batuan, dan pasir yang merupakan media bermain favorit hewan peliharaan. 


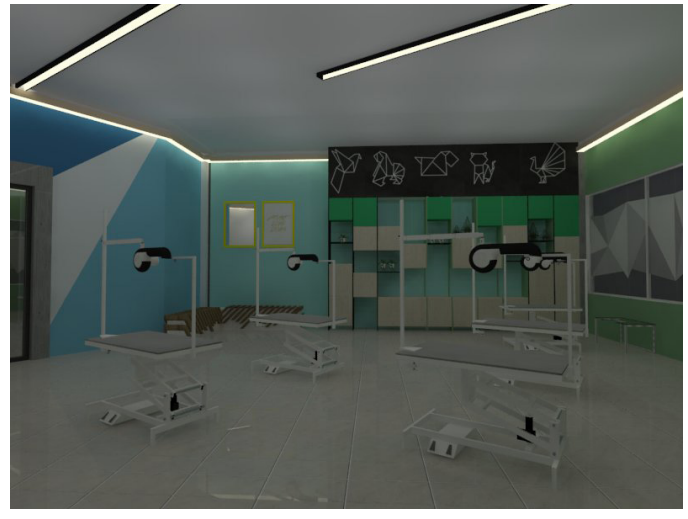

Gambar 11. Care Area

Dinding menggunakan batu bata plesteran dengan finishing cat dinding. Pilihan warna dinding padar area ini memadukan dua skema warna Dewy blue dan Green lush dari Nippon Paint Colour Collection. Pilihan warna biru memberikan efek sejuk dan tenang pada ruangan sehingga cocok diaplikasikan pada area ini. Warna hijau-kuning memberikan suasana natural, nyaman, dan tenang. Hal ini disesuaikan dengan psikologi hewan (anjing).

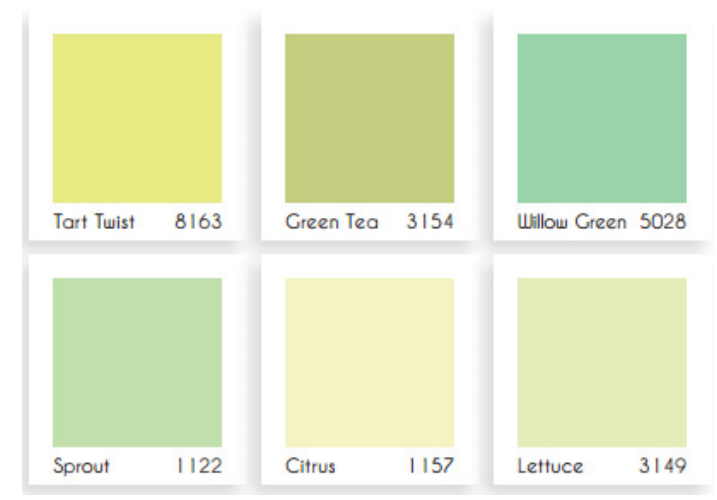

Gambar 12. Pilihan warna dinding pada Care Area

Pada bagian ceiling menggunakan material gypsumboard Ceiling menggunakan material gypsumboard sebagai material utama. Area ini pengisi ruang berupa peralatan grooming sudah sudah memenuhi ruangan, sehingga untuk memberikan efek ringan ceiling sengaja dibiarkan kosong.

\section{Area Medis}

\section{a. Area Medis Khusus Kucing}

Area medis ini merupakan area khusus kucing. Pada area ini terdiri oleh beberapa ruang yaitu, ruang periksa/ konsultasi, ruang isolasi, ruang bedah, ruang perawatan intensif/ pasca operasi. Material lantai yang digunakan pada area ini adalah lantai ceramics tile dengan gloss finishing untuk menunjang kesan bersih.

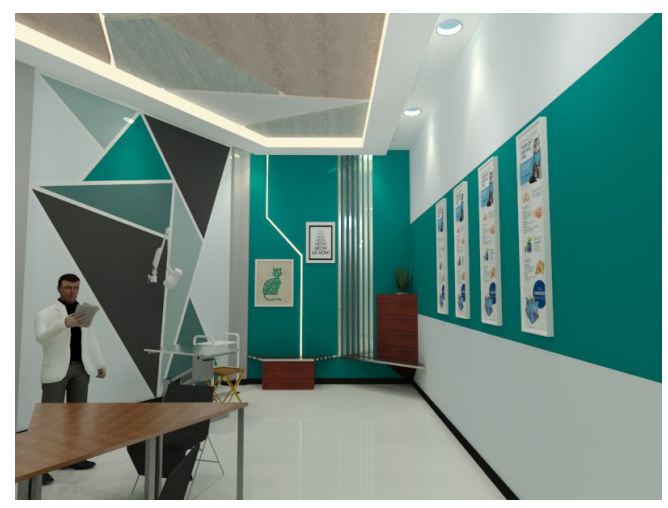

Gambar 13. Pilihan warna dinding pada Medic Area

Dinding menggunakan skema warna dari katalog Nippon Paint sebagai acuan warna. Dipilih warna-warna bernuansa tosca yang merupakan percampuran dari hijau dan biru, sesuai dengan psikologi warna. Untuk menonjolkan tema pada beberapa sisi dinding menggunakan teknik decorative wall paint mengunakan pola menyerupai lipatan-lipatan kertas.
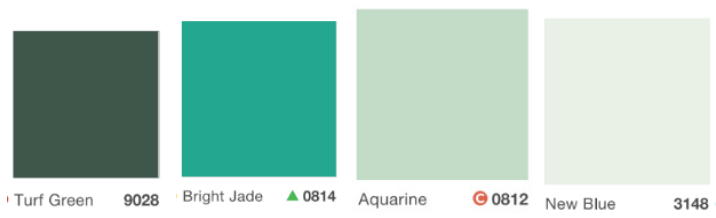

Gambar 13. Pilihan warna dinding pada Reception Area

Ceiling menggunakan material gypsumboard sebagai material utama, dengan aksen pola menyerupai lipatan kertas origami pada downceiling. Downceiling menggunakan finishing $h p l$ sheet dengan beberapa warna 
yang berberda untuk mempertajam bentuk pola.

\section{b. Area Medis Khusus Anjing}

Area medis ini merupakan area khusus anjing. Pada area ini terdiri oleh beberapa ruang yaitu, ruang periksa/ konsultasi, ruang isolasi, ruang bedah, ruang perawatan intensif/ pasca operasi. Material lantai yang digunakan pada area ini adalah lantai ceramics tile dengan gloss finishing untuk menunjang kesan bersih.
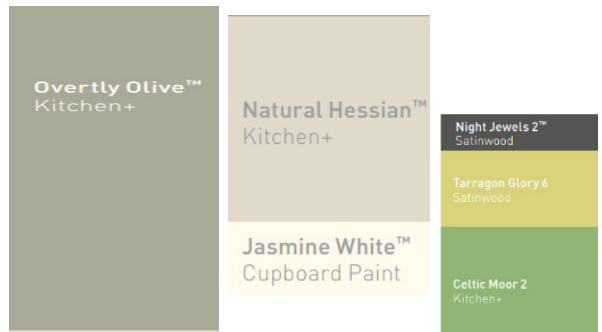

Gambar 14. Pilihan warna dinding pada Medic Area

Dinding menggunakan skema warna dari katalog Dulux National sebagai acuan warna. Dipilh nuansa warna hijau dipadukan dengan warna netral memberikan nuansa sejuk dan tenang namun tetap menarik perhatian. Pada bagian ceiling menggunakan material gypsumboard Ceiling menggunakan material gypsumboard sebagai material utama.

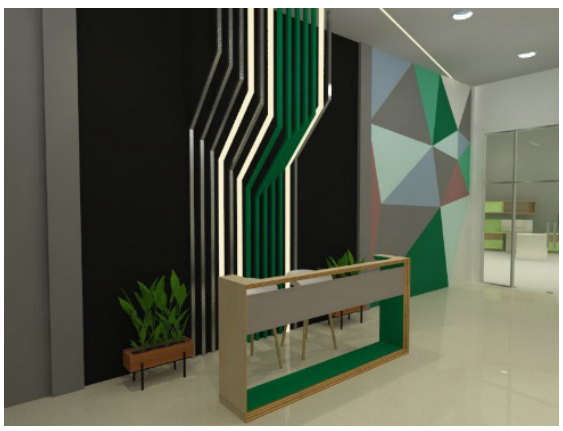

Gambar 15. Pilihan warna dinding pada Medic Area

\section{Office}

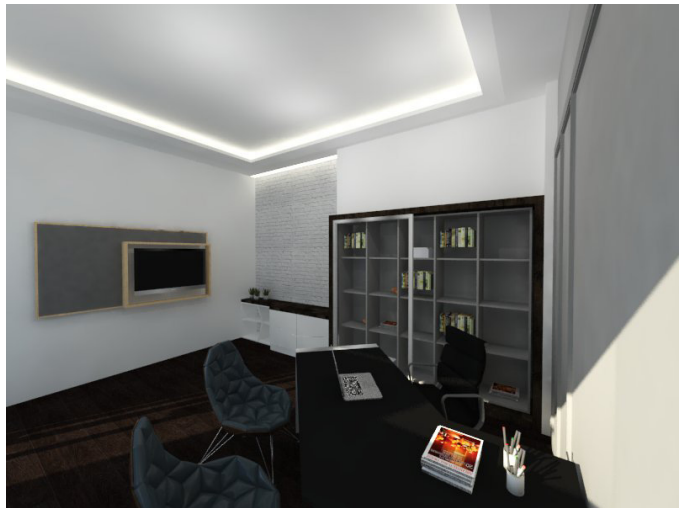

Gambar 16. Pilihan warna dinding pada Office

Dinding office menggunakan material bata plesteran dengan finishing cat putih. Dinding bagian bawah dilapisi batu alam setinggi $1 \mathrm{~m}$. List lantai menggunakan material kayu. Pada salah satu sudut ruang menggunakan batu bata ekspos sebagai aksen.
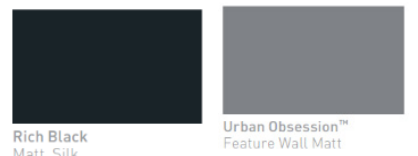

Gambar 17. Pilihan warna dinding pada Medic Area

\section{Meeting Room}

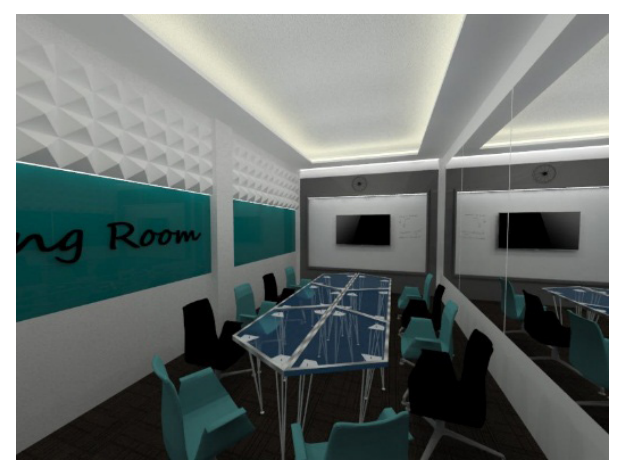

Gambar 18. Meeting Room

Pada altenatif I menggunakan dinding batu bata plesteran dengan finishing cat tembok warna light blue. Dinding dikombinasikan dengan panel akustik dari Baux berbentuk pyramid yang ditata sebanyak sepertiga bidang dari dinding dilanjutkan dengan panel pve yang 
sedikit glossy berwarna toska, sedangkan pada dinding lainnya menggunakan kaca sebagai material agar ruangan tampak luas.
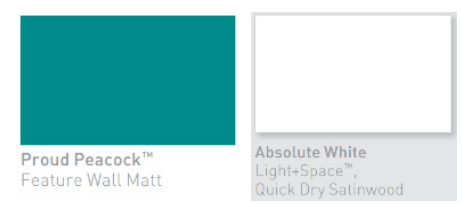

Gambar 19. Pilihan warna dinding pada Meeting Area

\section{Meeting Hall}

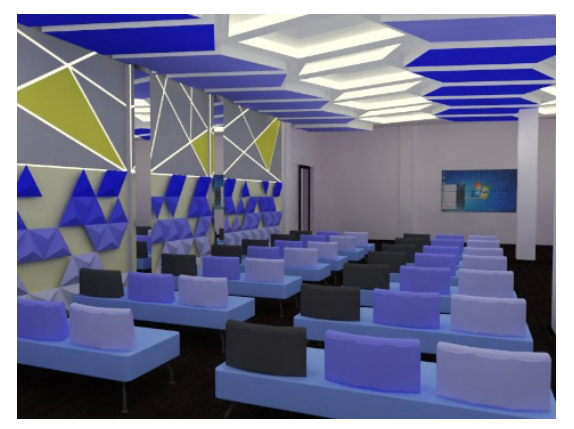

Gambar 20. Pilihan warna dinding pada Meeting Hall

Dinding menggunakan batu bata plesteran dengan finishing cat tembok berwarna putih dan abu-abu. Sepertiga bidang dinding dipasang panel akustik dari Baux yang dipasang secara khusus agar tidak monoton. Sisa bidang dinding lainnya menggunakan cat yang dipasang dengan pola tertentu yaitu lipatan origami. Skema warna biru dan kuning menjadi acuan dinding ruang ini.

\section{KESIMPULAN}

Perancangan Interior Pet Medicare di Kota Blitar merupakan merupakan salah satu upaya guna memenuhi kebutuhan fasilitas hewan, khususnya hewan piaraan di Kota Blitar. Keseluruhan kebutuhan hewan piaraan yang terangkum didalamnya meliputi pelayanan kesehatan (Medic) berupa klinik hewan, jasa perawatan kecantikan (Grooming) atau salon hewan dikemas dalam satu tempat atau lebih dikenal dengan istilah one stop service. Selain guna memenuhi kebutuhan hewan peliharaan, keberadaan Pet Medicare ini juga sebagai forum berkumpulnya para tenaga ahli dibidang kesehatan khususnya kesehatan hewan (Veteriner).

Guna mendukung aktivitas yang sesuai dengan karakteristik kegiatan dalam Perancangan Interior Pet Medicare di Kota Blitar ini menggunakan beberapa pendekatan diantaranya Pendekatan Fungsi, Pendekatan Ergnomi, Pendekatan Tema dan Gaya, serta Pendekatan Warna. Pendekatan Fungsi yang mengelompokkan pembagian fasilitas berdasarkan jasa yang ditawarkan pada Pet Medicare, Pendekatan ergonomi yang menjadi acuan standarisasi dalam mengolah ruang, furniture, serta sirkulasi dan besaran ruang yang diperlukan dalam beraktivitas pada Pet Medicare. Pendekatan tema dan gaya yang menjadi dasar pemikiran penerapan desain yang sesuai dengan objek garap yaitu dipilihlah tema origami yang memiliki bentuk dominan mengadopsi hewan dengan visualisasi unsur garis pada origami yang tegas, unik, dan beragam bentuk cocok dengan gaya kontemporer sehingga sangat pas jika diaplikasikan pada perancangan ini. Pendekatan warna digunakan untuk mengidentifikasi skema warna yang digunakan, terdapat kriteria khusus penglihatan anjing dan kucing yang mengalami buta warna parsial yaitu tidak dapat membedakan warna merah, untuk kucing hanya dapat melihat skema warna biru dan hijau, sedangkan anjing dapat membedakan warna hijau, biru, dan kuning. Sehingga pada Perancangan Interior Pet Medicare dengan Tema Origami di Kota Blitar ini menggunakan skema warna hijau, biru, kuning, dan sentuhan warna netral seperti hitam, putih, dan kecoklatan.

Adapun objek garap dalam Perancangan Interior Pet Medicare di Kota Blitar adalah 
1. Reception Area

2. Area Perawatan (Grooming, Play Space)

3. Area Medis

4. Store

5. Ruang Serbaguna

6. Office

7. Meeting Room

8. Service Area

\section{DAFTAR PUSTAKA}

\section{Buku :}

De Chiara, Joseph dkk. 1992. Time-Saver Standars for Interior Design and Space Planning. Singapore: McGraw-Hil.Inc

D.K. Ching, Francis. 2011. Desain Interior Dengan Ilustrasi edisi kedua. Jakarta: Erlangga.

D.K. Ching, Francis. 2008. Arsitektur Bentuk, Ruang, dan Tatanan edisi ketiga. Jakarta: Erlangga.

D Susanti. 2011. Pusat Fashion Kontemporer Yogyakarta. Yogyakarta: Universitas Atma Jaya

H.M. Ramli. 2012. Fisika Bangunan. Bogor : IPB Press

Ika Ruhana. 2012. Struktur dan Desain Organisasi. Jurnal Online Universitas Brawijaya, Malang
Marizar, Eddy. 2005. Designing Furniture. Yogyakarta: Media Presindo Yogyakarta Marlina, Endy.2008. Panduan Perancangan Bangunan Komersial. Yogyakarta: ANDI

Martha Christiani. 2012. Melipat Kertas untuk Anak Usia Dini. Buku Ajar PAUD Bab IV, Yogyakarta: Universitas Negeri Yogyakarta.

Panero, Julius dan Martin Zelnik, Human Dimension \& Interior Space : A Source Book of Design Reference Standards, Jakarta.Erlangga.

Patrycia Zharandont. 2015. Pengaruh Warna Bagi Produk dan Psikologis Manusia. Bandung : Universitas Telkom.

Peraturan Menteri Pertanian. 2010. Peraturan Menteri Pertanian Nomor:02/Permentan/ OT.140/1/210 tentang Pedoman Pelayanan Jasa Medik Veteriner. Jakarta : Kementrian Pertanian

Santoso, Bobby, N.S. Budiana. 2015. Anjing Trah Kecil. Jakarta: Agriflo Penebar Swadaya Grup

Suptandar J. Pamudji. 1999. Desain Interior. Jakarta: Djambatan

Sunarmi. 2008. Buku Pegangan Kuliah Metodologi Desain. Surakarta: STSI Surakarta. 


\section{Sumber Internet:}

Kota Blitar (http://www.surabaya.bpk. go.id/?page_id=8105. diakses 12 Desember 2015)

h t t p : // w w w.daudesain.com/ Arsitektur?arsitektur-kontemporer.html diakses pada 15/11/2016 pukul 22:12 WIB

www.wahana-arsitektur-indonesia.blogspot. com diakses pada 12/12/2017 pukul 16:00 WIB

\section{Narasumber:}

Aris Setyawan, A.Md. , Radiografer bagian instalasi radiologi dan elektromedik di Rs Jiwa Menur Surabaya (J1 Raya Menur 120 Surabaya)

Bayu Kinantoko, Mahasiswa Kedokteran Hewan di FKH Unair Surabaya.

drh. Lilik Rifqyanta, Dokter Hewan di Klinik Hewan Jogja, Condongcatur- Yogyakarta drh. Chandra Kurniawan, dokter hewan di Klinik Hewan dan Petshop Kawatan, Surakarta. 